\title{
MPRA
}

Munich Personal RePEc Archive

\section{The Nature and the Extent of the Market for Technology in Biopharmaceuticals}

\author{
Arora, Ashish, Gambardella, Alfonso, Pammolli, Fabio and \\ Riccaboni, Massimo \\ IMT Institute For Advanced Studies, Lucca
}

December 2000

Online at http://mpra.ub.uni-muenchen.de/15977/ MPRA Paper No. 15977, posted 30. June 2009 / 09:58 


\title{
THE NATURE AND THE EXTENT OF THE MARKET FOR TECHNOLOGY IN BIOPHARMACEUTICALS
}

\author{
Ashish Arora \\ Heinz School, Carnegie Mellon University, Pittsburgh PA \\ ashish@andrew.cmu.edu \\ Alfonso Gambardella \\ Sant'Anna School of Advanced Studies, Pisa, Italy \\ agambardella@info-net.it \\ Fabio Pammolli \\ University of Siena, Italy \\ pammolli@cln.it \\ Massimo Riccaboni \\ Sant'Anna School of Advanced Studies, Pisa, Italy, \\ and University of Siena, Italy \\ riccaboni.massimo@libero.it
}

December 2000

This paper is part of the activities of the EPRIS Project (European Pharmaceutical Regulation \& Innovation Systems), University of Siena, Italy. We also acknowledge financial support from the CNRS Program "Les Enjeux Economique de 1'Innovation". The paper benefitted from comments and suggestions of the participants in the International Conference on "Technology Policy and Innovation: Economic and Historical Perspectives", Paris, Maison de la Chimie, Centre International de Congres, 20-22 November 2000, and in the EPRIS Annual Meeting, London 15-16 December, 2000 . 


\begin{abstract}
This paper explored an unusually comprehensive dataset of more than 2,000 drug R\&D projects all over the world during the 1990s. This enabled us to characterise several features of the innovation process in pharmaceuticals, particularly the different role and comparative R\&D performance of the large established drug companies vis-à-vis smaller high-tech specialist firms - the so-called New Biotechnology Firms (NBFs). Our results can be summarised as follows:
\end{abstract}

a) The NBFs are largely an American phenomenon. More than half of the drug R\&D projects originated in the US are by NBFs, while almost $90 \%$ of the drug R\&D projects originated in Europe are from established pharmaceutical firms;

b) Collaborative R\&D projects are consistently more likely to occur in the US than in Europe. However, in-house projects are a significant majority of the drug R\&D projects that entered the clinical stages.

c) The established pharmaceutical companies have comparative advantages with respect to the NBFs in drug development (clinical trials). In drug discovery there is no advantage related to scale. Unlike clinical developments, where the large firms seem to have superior capabilities when compared to the NBFs, in discovery there is no inherent superiority (in terms of ultimate probability of success of the compounds) of either the NBFs or the large firms.

d) The NBFs are not specialized in more risky R\&D projects. In fact, more risky drug projects (i.e. drugs for which there is no or there are few existing remedies) are more likely to be undertaken by the larger pharmaceutical companies. This suggests that scale, market power, and the ability to moblise large amounts of resources are key factors in enabling the firms to sustain such higher risks.

e) Other things being equal, the projects originated by the NBFs are more likely to fail in the earlier clinical stages. This suggests that the NBFs perform a good deal of exploration without incurring the higher costs of failing at later stages. 


\section{INTRODUCTION}

Technological collaborations, R\&D agreements, licensing and the exchange of technology among independent parties have become common phenomena in recent years. (See for instance Teece, 1986; Kogut, 1988; Hagedoorn, 1992; Hagedoorn and Schakenraad, 1994.) In many industries, and particularly in many high-tech industries, one observes the rise of smaller high-tech firms whose main competence is technology. Typically, these firms supply their technologies through licensing or more elaborated forms of collaboration within full fledged "markets for technology". (Arora, Fosfuri, and Gambardella, 2000.) As argued by Gans, Hsu and Stern (2000), when technological appropriability is strong, these firms tend to act as specialized technology suppliers to the larger established firms which operate in the downstream markets. When technological appropriability is weaker, they tend to appropriate rents from their mastery of the technology by moving downstream, and by competing with the established firms.

Biopharmaceuticals is a quintessential example of the development of technological collaborations, as well as of technological competition, between larger established firms, and a set of new, smaller firms specialized in technology. The story of the New Biotechnology Firms (NBFs) has been told by several authors (e.g. among others, Orsenigo, 1989; Gambardella, 1995). After the foundation of Genentech in 1976, a wave of NBFs were founded in the 1980s, and many others have been founded during the 1990s. The NBFs are specialized in the early stages of drug R\&D. Their comparative advantage is in the application of the new biological technologies and the life sciences to drug discovery, and to other areas like agricultural chemicals, food, 
environment, etc.. In pharmaceuticals, the NBFs often lack the resources to conduct the far more costly clinical trials to obtain the market approval for their new compounds. They also have a comparative disadvantage in large scale commercialization of the new drugs. Clearly, the large firms, and especially the large drug multinationals, keep significant in-house scientific and technological expertise. However, the NBFs often represent a useful source of new compounds and more generally of external technological and scientific competences.

The story of the NBFs raises several questions. Particularly, we lack a systematic assessment of issues like - What are the main characteristics and comparative advantages of the larger and smaller firms in the innovation process? Do the larger firms have comparative advantages in downstream R\&D activities, while the smaller firms have comparative advantages in upstream research because of their more suitable organizational structures and systems of incentives (e.g. Arrow, 1983; March and Levinthal, 1993)? Are the smaller high-tech firms taking up more risky projects (e.g. Arrow, 1983; Holmstrom, 1989)? Are the smaller firms providing a greater deal of "exploration" by initiating several new projects which tend to end up earlier, thereby avoiding more costly failures at later R\&D stages? Since the life sciences are said to offer a more scientific approach to drug discovery, potential failures can be detected earlier because of the better understanding of the underlying process. One may then expect that the projects of the NBFs, which are more specialized in the life sciences, fail earlier, with implied cost savings from avoiding later failures. Another question is whether collaborative and in-house R\&D projects exhibit different probabilities of success. As we shall discuss in the paper, there are reasons in favour of either one of 
the two R\&D governance structures, and the only empirical study we know on this issue found that internally developed compounds are more likely to succeed (Pisano, 1997).

This paper employs a comprehensive database of drug $R \& D$ projects all over the world during the 1990s. Our sample includes projects that entered at least the first stage of the clinical trials (clinicals I). The database reports systematic information about such projects, like the therapeutic class of the compound which is being tried; the stage (clinicals I, II, III) in which the project failed, or whether it was eventually approved for commercialization; the company that originated the compound, and the one that developed it (which will be the same company in the case of in-house projects); the R\&D stage (clinicals I, II, III) in which the compound was licensed; the country in which the trials were conducted, and in which the compound was approved. As we shall discuss in the next section we used only the projects which were terminated (either that failed or that ended up successfully). Our sample is then composed of 2078 projects. The main goal of the paper is then to exploit the potential of our database to provide a systematic and comprehensive assessment of the technological collaborations in this industry, the role and the comparative advantages of the smaller high-tech NBFs vis-à-vis the established pharmaceutical companies, along with other aspects of the nature and the organization of the innovation process in this sector.

Of course, biopharmaceuticals is peculiar in that, compared to other high-tech industries, its R\&D activities unfold "linearly" from discovery to the various clinical tests. This helps our empirical analysis as it avoid the complications associated with the far more convoluted - or "chain-linked", as Kline and Rosenberg (1986) put it - R\&D 
processes of industries like electronics. Here, for example, we can distinguish fairly neatly between an early, upstream research stage and the downstream ones. However, the very fact that in this industry we can naturally separate features like the upstream $v s$ downstream R\&D stages, or the activities that different types of firms (e.g. large and small) do, suggests that it may provide a meaningful perspective to evaluate more generally the nature of these processes. For example, questions like whether or not biotech firms perform more risky projects, or whether they are specialized in upstream research, or about the nature of the in-house vs licensing process and the potential differences in their probability of success, can be informative about similar processes in other industries.

The paper is organized as follows. The next section presents our database, and it discusses our sample of projects. Sections 3-8 empirically assess various issues about technological collaborations in the pharmaceutical industry. Section 3 looks at the share of compounds developed in collaboration $v s$ those developed internally by the firms, and the role of the NBFs and the larger firms. Section 4 examines whether the NBFs originate more risky technological projects. Section 5 tests the differences in the probability of success of the licensed vs in-house compounds. Section 6 and 7 assess the comparative advantages in upstream research and in drug development of the NBFs and the larger firms. Section 8 examines whether the NBFs projects that failed, tend to fail at earlier research stages. As noted, this may be a consequence of the more scientific content of the technology in which the NBFs are specialized. The concluding section summarizes the overall picture about the nature of the drug $R \& D$ process that emerges from our analysis, along with the differential features of the firms involved. 
The Appendix develops further details about our results, and particularly about the R\&D specializations of the larger and the smaller innovators in our sample.

\section{THE SAMPLE OF DRUG R\&D PROJECTS}

Our sample is drawn from the Pharmaceutical Industry Database (PHID) built at the University of Siena. PHID combines several sector-specific proprietary datasets about R\&D activity, collaboration and final drug markets with data from public sources as well as companies confidential information and press releases. PHID covers 11418 R\&D projects developed by 2262 organizations including: 427 pharmaceutical companies $^{1}, 1222$ biotech firms ${ }^{2}$ and 613 universities and other public and private research centers between 1989 and 1999. Twenty-two percent of all the projects in our database were developed in collaboration by two or more partners.

For each R\&D project, the database provides the following information:

1) Originator. Firm/institution that launched the R\&D project on a new chemical compound with potential pharmacological activity (or known chemical compounds for different pharmacological targets). Typically, it is the holder of the patent on the new compound (or the new indication).

2) Developer. Firm/institution that developed the project. This is the same as the Originator for the in-house projects. For the licensed compounds, the Developer is

\footnotetext{
${ }^{1}$ Subsidiaries, divisions and research laboratories of pharmaceutical firms are included. For each project of these subunits our database reports the ultimate parent company.

${ }^{2}$ We defined biotech companies to be all the companies in our database that were founded after 1976 (the year in which the first biotech company, Genentech, was founded) and that were originators of projects in the database that applied biotechnological methodologies to the discovery and development of new drugs. We also checked our database to avoid that joint-ventures among larger established companies fell into
} 
the licensee who is entitled to develop it further. Frequently the relationship between Originators and Developers is not just a pure licensing contract. In $67 \%$ of the cases it amounts to an R\&D collaboration with fairly complex contractual and organizational settings. Moreover, $12 \%$ of the collaborations are between one Originator and many Developers. In these cases we considered different projects for different Developers. ${ }^{3}$

3) Therapeutic Categories: Projects have been classified according to their targets in terms of likely therapeutic markets. We adopted the ATC (Anatomic Therapeutic Classification) at the $3^{\text {rd }}$ digit level. For example, HIV-antiviral correspond to the ATC3 class $\mathrm{J}^{\mathrm{CC}}$. $^{4}$

4) Pharmacological Actions: The main pharmacological activity of the compounds is described in standard terms. Back to the HIV-antivirals example, we can discern proteinase inhibitors from reverse transcriptase inhibitors and other products with different biological targets.

5) Development History: The PHID database monitors the whole development history of the projects starting form the patenting date of the compound (priority and issue), through preclinical and clinical development stages (I, II, III), to registration and final launch on the market. For unsuccessful projects it registered the stage in which they have been discontinued.

this category. After inspecting our sample, we were confident that this criterion enabled us to single out the NBFs.

${ }^{3}$ These are non-exclusive licensing contracts in which the Originator typically licenses the compounds to several Developers who test it for different indications/pathologies. The testing of the same compound for different indications/pathologies also justifies the fact that we treat them as different projects.

${ }^{4}$ The Anatomical Classification of Pharmaceutical Products has been developed and maintained by the European Pharmaceutical Marketing Research Association (EphMRA) starting from 1971. A Classification Committee has been constituted to takes care for new entries, changes and improvements. The $1^{\text {st }}$ level of the Anatomic Therapeutic Classification indicates the anatomical main group $(\mathrm{C}-$ Cardiovascular System). The $2^{\text {nd }}$ level identifies the main therapeutic groups (C1 - Cardiac Therapy). Finally, the $3^{\text {rd }}$ level separates out the pharmacological/therapeutic subgroups (C1B - Anti-Arrhythmics). 
6) Collaborations and licensing activity: For the licensed compounds, PHID records the development stage (clinicals I, II, or III) at which the collaboration agreement was signed, and the type of collaboration that was specified by the parties.

7) Country of clinical trials: PHID also reports the countries in which the clinical trials were conducted, and for the successful projects those in which the products were approved. As we shall see below, we only look at the projects in which the Developer is a US or European company. In the vast majority of cases, the companies from these regions run the clinical trials and obtained approvals in their home country as well. We then took the home country of the company as the country of the trials. ${ }^{5}$

Moreover, for the companies included in our database we collected information about: (a) year of founding; (b) nationality; (c) number of employees; (d) total revenues (health and consolidated); (e) R\&D expenditures (health and consolidated); (f) sales in seven countries (USA, Canada, UK, France, Germany, Spain and Italy).

For the purposes of this paper we extracted from PHID a specific sample. First, we disregarded all the projects that had not yet reached the clinical trials. Firms may differ in their definition of an in-house projects, and they may have different attitudes about releasing news about their internal R\&D activities. By contrasts, when they enter the clinical trials, the information about projects is registered and becomes public domain. This also entails a fairly standard definition of what constitutes a drug R\&D project.

The $3^{\text {rd }}$ ATC level is a widely accepted standard (applied for instance by Antitrust authorities around the world) to classify products for purposes of identifying the manufacturing market in pharmaceuticals. 
Second, our sample is composed of all the projects that were terminated. These are all the projects in the database for which we know that the compound was either successfully approved for marketing, or it was discontinued at clinicals I, II, or III. The database does not tell us whether the project actually failed. However, managers in the pharmaceutical industry told us that it is rare that a project that passed some clinical test was not moved to the next stage. This rules out that projects may overcome some clinical tests but were discontinued because of the lack of funds to conduct the later clinical trials. Relatedly, it rules out cases of strategic behavior on the part of the pharmaceutical companies, which may choose not to enter a later trial because they have reasons to believe that the compound may fail at the later stages - viz. the expected value of the next trial is not worth its costs, in spite of the fact that the compound passed the earlier stage. In short, the compounds that were discontinued can be treated as genuine failures at that stage of the clinical tests. ${ }^{6}$

Third, we restricted our sample to the projects whose trials were conducted in the US or in one of the 15 countries of the European Union plus Switzerland and Norway. When we selected only the leading European countries, notably the UK, France and Germany, the differences in our empirical results were marginal. Moreover, as we shall see, our results are fairly similar when we restrict our analysis to trials in the US by the US firms. We also confined our sample to projects in which the firm developing the

\footnotetext{
${ }^{5}$ In few cases the home country of the company was not one in which the firm run the clinical trials. In these cases, we assigned the nationality of the trials to be the US if there were US trials or US approval, or Europe if there were trials or approval in one of the European countries and not the US.

${ }^{6}$ Pisano (1997) also ruled out from his sample all the projects that were not terminated.
} 
compound is from the US, one of the Europe-15 countries, Switzerland or Norway. By this, we mean companies with their headquarter in one of these countries.

The reason why we did not include trials conducted in other countries is that the European and US trials are likely to be more stringent. This prompted us to eliminate the companies from the other countries. The higher costs of international trials for these companies may prompt them to try in the US or Europe only their best compounds, with implied upward bias in their probability of success. We noted that Japanese companies received many international licenses which were probably licenses for compounds that were already commercialised elsewhere. These were unlikely to be genuine new compounds. To avoid this and related biases we chose to eliminate Japanese companies (and the Japanese trials) altogether. We also excluded all the projects licensed by the established pharmaceutical companies to other companies. Since it is unlikely that an established pharmaceutical firm licenses a product to another firm without commercializing it itself, these are probably not new R\&D projects. Most likely, these are projects developed earlier by the licensor, and then tried again, possibly in his home country, by the licensee. Therefore, all the licensed compounds in our sample come either from universities or from NBFs. In addition, we carefully inspected all the remaining collaborations in our sample to verify their genuine $R \& D$ content. Our final sample is composed of 2078 projects. 


\section{THE NBFs AS AN AMERICAN PHENOMENON}

It is typically argued from several accounts of this industry that the NBFs are largely an American phenomenon. Our analysis begins by checking the prevalence of the NBFs in the US market, and the extent of the difference between the US and Europe in this matter.

Table 1 reports the percentage of projects in our sample originated by established pharmaceutical companies, NBFs, and universities. The Table also reports the percentage of licensed projects over the total projects in the sample, and the percentage of successful projects, which gives an idea of the orders of magnitude of the unconditional probabilities of success in our sample.

\section{TABLE 1 ABOUT HERE}

The Table distinguishes between projects developed by US-based companies in the US (i.e. trials conducted in the US), and projects developed by European-based companies in Europe (trials in Europe). The reason why we restricted to projects developed by the companies in their own regions is the one mentioned earlier that companies may develop in other countries only the compounds with higher expected value. However, we also tried several other cases (viz. trials by any company in the US or in Europe, as well as the full sample). The picture that emerges is basically the one offered by the present Table. For example, we found that the European-based companies normally develop their compounds in Europe, and similarly for the US companies. Since our data focus on the projects that were first developed somewhere, this suggests that, as 
expected, the companies from either regions first develop their compounds in their own region. This also implied that we only added few observations when we looked at the projects by European or US companies in the US, as compared to the US trials by the US firms only, and similarly for the European case.

The Table shows that there are many more projects originatd by the NBFs in the US than in Europe, and there are many more US than European NBFs. If we look at the first column of Table 1 (US trials by US firms), more than half of the projects were originated by the NBFs, compared to $11.5 \%$ of the projects in Europe. As noted earlier, the difference in the percentages does not change if one conditions only on whether the companies are US or European (wherever they do the trials), or on whether the trials are conducted in the US or Europe.

Probably as a consequence of the larger presence of NBFs in the US market, the share of licensed projects is higher in the US (or in the case of the US companies). Overall however, the percentage of licensed compounds is small $-7.5 \%$ in the US and $2.1 \%$ in Europe. One could argue that companies may record as internally developed compounds any sort of "small" projects that they have launched or that they may even have just in their mind, or in the mind of their scientists. By contrast, a compound that was developed through a formal collaboration is likely to be a more sizable and realistic project. As discussed earlier, our database is composed however, of projects that entered at least clinicals I. This means that they are all projects of some scale and magnitude, which cannot be mere ideas. As a result, the percentages shown in the Table may be genuine shares of the two types of projects. 
From inspecting our data, we also noted that the share of projects in collaborations has increased significantly for projects launched after the mid-1990s. Many of these projects are not in our sample because they have not been terminated. The percentage of projects in collaborations over the total number of projects still under development is higher (19.95\%). This suggests that the importance of technological collaborations and the market for technology might have increased in the 1990s, as also argued elsewhere for this and other industries (Arora, Fosfuri and Gambardella, 2000). Finally, Table 1 shows that the probability of success for a compound that enters clinicals I is of the order of $10 \%$.

\section{4. “RISKY” PROJECTS}

It has been argued that smaller high-tech firms have a greater propensity to undertake more risky technological projects. For one reason, their informal and less hierarchical organizational structures favor the development of new ideas. Similarly, their internal incentive system is more likely to induce risky ventures than the hierarchical structure of the larger firms.

We asked a pharmacologist to rank the 3-digit ATC class assigned to the projects in terms of their degree of risk. ${ }^{7}$ At the 3 -digit level, therapeutic classes reflects quite closely to the basic degree of risk and innovativeness of the compounds. For each new product the ATC Scientific Committee decides if it can be classified in a class that already exists. If not, new groups/classes are created for new markets for which these 
products are indicated. It is possible to identify according to standard pharmacological criteria the classes with a higher innovativeness content. Specifically, our pharmacologist ranked the 3-digit therapeutic class of the projects in our sample on a 05 scale. She assigned 0-1 to therapeutic classes that concern pathologies that are fairly well known and for which there are quite a few existing remedies on the market; 2-3 were assigned to therapeutic classes in which the pathology was less well known, and for which there are few remedies on the market; 4-5 cover therapeutic classes in which the pathologies are largely unknown, and there are very few or no remedies (e.g. Alzheimer).

Moreover, since there are projects that span more than one therapeutic class, we took the average score of the classes assigned to the project, and associated that average value to it. In order to keep a fair number of projects per class of risk, we grouped our risk classes in three main categories. We defined $\mathrm{R} 1$ to be our low risk class. This includes all the projects with original score between 0 and 1.68; R2 is the intermediate risk class, for projects whose original score was between 1.68 and 3.34; R3 is the high risk class, for projects whose original score was between 3.34 and 5. As a check for the validity of our classification, we computed the mean probability of success of our projects in the three classes. When considering only the projects developed by the US firms from clinical trials in the US, the expected probability of success for R1, R2, and R3 projects are respectively $15 \%, 9 \%$, and 4\%; for projects developed by the European firms in Europe, they are $15 \%, 12 \%$, and $7 \%$. This suggests that our risk classes do capture the lower probability of success of taking $R \& D$ projects to completion as one moves from R1 to R3.

\footnotetext{
${ }^{7}$ There are 193 3-digit ATC classes in our sample of projects.
} 
To assess the propensity of different types of agents to launch risky project, we report the cross-tabulation of the number of projects in classes R1, R2 and R3 originated by the NBFs, the established pharmaceutical companies and the universities. Table 2 employs the sample of projects in which the developer is a US firm in the US. Since most of the NBFs are from the US, this ruled out potential biases due to international projects. For comparison, Table 3 reports the same data for the full sample.

\section{TABLES 2 AND 3 ABOUT HERE}

The interesting result of Tables 2 and 3 is that the NBFs launch relatively more projects in R1 than in R2 and R3, while the larger firms (and the universities) originate comparatively more projects in R2 and R3. This is true both in Table 2 (US firms doing trials in the US) and 3 (full sample). Using the data in Table 2, the shares of R1, R2, and R3 projects originated by NBFs are respectively $68.7 \%, 56.4 \%$, and $45.7 \%$. By contrast, the shares of $\mathrm{R} 1, \mathrm{R} 2$, and $\mathrm{R} 3$ projects originated by a large company or a university are: $27.6 \%, 37.4 \%, 48.6 \%$, and $3.7 \%, 6.3 \%, 5.8 \%$.

This result contradicts the view that smaller high-tech firms undertake relatively more risky $\mathrm{R} \& \mathrm{D}$, and do more exploration in less known technological territories. It also confirms the point made quite a few years ago by Schwartzman (1976) that the large companies are the more typical vehicle for conducting risky R\&D in the drug industry. Put differently, these results confirm that the capability of sustaining high levels of technological risk, such as the one that is necessary to cope with major pathologies with 
no existing remedies, are more likely to be borne by larger companies with established financial assets and commercialization capabilities. At the same time, these results suggest that what the NBFs are more typically doing is to produce existing remedies using the new biological technologies. They do not tap risky business, but they typically use their expertise in the new technology to tap a market with relatively little risk (e.g. diagnostic kits, rare pathologies, etc.). ${ }^{8}$

\section{PROBABILITY OF SUCCESS: LICENSED VS. IN-HOUSE PROJECTS}

Are the licensed compounds more likely to be successful than the internally developed compounds? There are reasons for arguing both ways. For example, Pisano (1997) maintained that in the case of licensed compounds there could be a classical "lemon" problem. Asymmetric information implies that the licensor is more informed about the potential of her license. The licensees know this, and if there is no way in which the "good" licensors can distinguish themselves from the "bad" ones, the licensees are only willing to pay license fees that are equal to the expected value between the value of a potentially good compound and that of a potentially bad one. But this means that the licensors of good compounds do not realize the value of their license, while the licensors of bad compounds enjoy an extra rent. As a result, it is likely than on the market one observes a greater share of lemons than in the universe of projects as whole. Pisano tests this hypothesis by checking whether the licensed compounds have a lower probability of success than internally developed ones. By using data on about 300 drug

\footnotetext{
${ }^{8}$ See the Appendix for further details about the specializations of the NBFs and the larger firms in these areas of activity.
} 
R\&D projects he finds that internally developed projects have a higher probability of success than projects developed in collaboration with other parties.

But transaction costs may work the other way as well. For example, due to asymmetric information or other imperfections in the market for technology, licensed compounds have higher costs than internally developed ones. The higher costs are shared by the licensor and licensee. As a result, the expected value of the licensed compound must be higher than an equivalent in-house drug. Since we do not have a good measures for assessing the market size of the drug candidates, we test the hypothesis that licensed compounds have a higher probability of success. Another argument is that the licensed compounds have higher probability of success because of the higher efficiency of the R\&D process when associated with an effective vertical specialization in the drug innovation process. As suggested earlier, the NBFs can be more efficient in the discovery stages. If so, the compounds licensed by the NBFs (or the universities) are more likely to succeed.

When comparing the probability of success of in-house vs licensed compounds, one also needs to compare the right conditional probabilities. Compounds licensed at a given clinical stage have passed the earlier stages. Their probability of success is then the probability of success conditional on the fact that they passed such earlier stages. As a result, they should be compared with in-house projects conditional upon the fact that they have overcome the same earlier stages. Since our data provide the information about the stage at which the licensed compounds were licensed, we could compute the probability of success for compounds licensed at clinicals I, II and III. Since clinicals I 
is the basic clinical stage at which the projects in our sample were recorded, we compared the probability of success of the compounds licensed in clinicals I with the probability of success of the internally developed compounds in our sample. We then compared the probability of success of the compounds licensed in clinicals II with the in-house compounds that passed the clinicals I stage. Similarly, we compared the compounds licensed in clinicals III with the internally developed compounds that passed clinicals II.

The results are in Table 4. As we did earlier, we show both the results for the US companies running US trials, and those obtained using the full sample. The two samples show no qualitative difference in the results. Also, to avoid any potential bias in the data, the sample used in this and the next sections does not include the compounds developed by the universities (but it still includes compounds originated by universities and licensed to companies). This reduces our full sample from 2078 to 2036 projects. $^{9}$

\section{TABLE 4 ABOUT HERE}

Table 4 shows that the probability of success of the licensed compounds is systematically higher than that of the internally developed compounds. This contradicts the earlier finding by Pisano (1997) that licensed compounds are more likely to be lemons. By contrast, it suggests that either licensed compounds need to have a higher expected value to overcome transaction costs, or that licensed compounds are originated

\footnotetext{
${ }^{9}$ Since in the earlier section we were focusing on the originator capabilities there was no need for eliminating the projects developed by the universities.
} 
by companies that are more efficient in the earlier stages. In section 7 below, we show that the NBFs are not necessarily more efficient originators than the established companies (apart from possibly in class of risk R1). This suggests that it is transaction costs that makes licensed compounds more likely to be successful.

The Table also shows that the difference in the probability of success between licensed and internally developed compounds is quite pronounced. ${ }^{10}$ While one cannot exclude that our sample is biased in favor of the collaborative projects, this evidence would be consistent with the view that licensed compounds entail rather substantial transaction costs. As a matter of fact, the manger of an important US drug manufacturer told us that:
"In my experience we are very discriminating when it comes to choosing in-licensing partners, because the deal typically involves royalties on sales (therefore sharing the profits, while assuming almost all the development risks). With the inhouse compounds, we assume the same risks (resource requirements to develop compounds), but are assured that the profits are not shared."

First, this suggests that apart from asymmetric information and the like, such collaborative deals may entail long negotiations before they are concluded. More importantly, as our manager points out, the resource requirements that are necessary to develop a licensed drugs may not be substantially different from those of an in-house project. As the licensees have to share profits while still incurring the bulk of the R\&D

\footnotetext{
${ }^{10} \mathrm{We}$ also compared the average probability of success of the in-house compounds with that of the whole set of licensed compounds irrespective of the stage in which they were licensed. The probability of success in the case of licensing was still higher, and the differences were similar to those shown in Table 4.
} 
costs, the expected value of the deal has to be sufficiently high compared to an in-house projects. Given the potential market size of the compound, the higher expected returns are enhanced only if the probability of success of the in-licensed drugs is rather high. Note that the latter argument does not stem from transaction costs, but from the very fact that the licensee has to share the rents while incurring the bulk of the R\&D costs in any case. Thus, the need for being discriminating in the licensing process, which may imply long search processes and negotiations (transaction costs), along with revenue sharing, can make the sample of licensed projects a highly selected one, with related implications for the probability of success.

\section{ASSESSING DEVELOPMENT CAPABILITIES}

Different types of companies may have different comparative advantages in different stages of the innovation process. Most typically, the larger companies may have greater comparative advantages in downstream innovation development compared to upstream innovation activities. This is because downstream development activities are more likely to rely on scale and experimentation, and this favors companies that can mobilize enough resources for these purposes. By contrast, the flexible organisation of the smaller firms may be more suitable to enhance creativity, which is a key asset for the early stages of the research process. In this and the next section we test for the comparative advantages of the larger pharmaceutical firms and the NBFs in different stages of the drug innovation process.

In this section we focus on the development capabilities. In order to do so however, we cannot simply look at our sample of projects. This is because, for in-house projects, the 
probability of success of the compounds may be affected by the upstream capabilities of our companies, and this implies that we cannot disentangle their specific downstream capabilities. We focus on the licensed compounds. We argue that when the compounds are licensed, the "originator" capabilities are with the licensor. If development capabilities did not matter, we ought to observe that different companies would not have different probabilities of success once the compound is licensed. By contrast, if for licensed compounds there are differences in the probability of success, they can be attributed to differences in development capabilities.

We tested for such differences between the large pharma companies on the one hand, and the NBFs on the other. If the originator capabilities are assumed to be with the licensors, any remaining difference between NBFs and larger companies as licensees ought to be attributed to differences in development capabilities. Although we could do so in principle, we did not test for differences among developers of different nationalities (e.g. European and US firms). As noted earlier, this is because of the potential bias in the types of compounds that the companies of the two region develop in the other region. ${ }^{11}$

Table 5 reports probit estimations in which the dependent variable is whether the compounds were successfully marketed or not. The sample is composed of all the licensed compounds, and we run two separate regressions for the US companies running trials in the US and for the whole sample. Apart from risk class dummies (and a dummy for US trials in the full sample probit), we use a dummy for whether the

\footnotetext{
${ }^{11}$ As a matter of fact, we did find that the compounds of the European companies developed in the US have higher probability of success, and the same for the compounds developed by the US firms in Europe.
} 
company is a large pharmaceutical company rather than an NBF. The Table reports both the estimated probit parameters and the implied changes in the probability of success.

\section{TABLE 5 ABOUT HERE}

Table 5 shows that the large pharmaceutical companies are better developers. The result is statistically significant. Other things being equal, for trials conducted by the US companies in the US, the probability of success when the licensee is an established pharmaceutical firm is about $25 \%$ higher than an NBF. The result is similar for the full sample, although the difference in probability is smaller (15\%).

\section{ASSESSING THE ORIGINATORS CAPABILITIES}

To assess the originators capabilities, we run probit regressions with the dummy for successful projects as our dependent variable. Table 6 reports the results of four sets of probit regressions. The first two regressions use only the sample of projects developed by the US companies in the US, while the latter two use the full sample. In each of the two sets of regressions, the second regression eliminates projects originated by the universities to focus on the comparison between large pharmaceutical firms and the NBFs. ${ }^{12}$ The probit regressions include dummies for risk classes, and the full sample regressions include a dummy for clinical trials in the US. The Table shows both the estimated probit parameters and the implied changes in probability.

\footnotetext{
${ }^{12}$ The projects developed by the universities were eliminate altogether earlier - see section 5 above.
} 
TABLE 6 ABOUT HERE

The key result of Table 6 is that as originators, the NBFs are no better than the established pharmaceutical firms. Compounds with NBF as Originators have a mere 0.01 or 0.02 difference in probability of success compared to compounds originated by the larger firms, and this difference is not statistically significant. By contrast, the compounds originated by the universities have a statistically significant difference in probability of about 0.13 . The latter result probably reflects the fact that the universities do not have the type of organization and resources that are needed to test new compounds on a large scale. Thus, if a university starts the clinical trials, it is likely to do so because it has a potentially valuable compound. In short, with universities, the type of projects in our sample might be biased in favour of the more successful projects. Clearly, our finding would not either be inconsistent with the hypothesis that universities have better capabilities as originators. Ultimately, both factors probably contribute to the higher observed performance of the universities as originators.

The finding about the NBFs and the large firms needs some further comment. First, the results of the previous section showed that the large firms have higher absolute advantages downstream, while this section showed that they have no advantage as originators. Thus, the large firms have higher comparative advantages in downstream innovation development. This also suggests that scale is important in drug development, while it is not important in drug discovery. 
Second, the results in Table 6 do not account for possible differences between the NBFs and the large firms in different types of innovation projects. Table 7 then reports the sample averages of the probability of success for the large firms and the NBFs in our three risk categories R1, R2, and R3. We report the results for both the sample of the US firms running US-based clinical trials, and for the full sample.

\section{TABLE 7 ABOUT HERE}

Table 7 shows that the NBFs have no advantage in categories R2 and R3, but they do have an absolute advantage in R1. Although not statistically significant, the point estimate indicates that in R1 the probability of success of a large US pharma in the US is about 0.10, while for an NBF it raises to 0.16. For R2 and R3, large firms have probabilities of success equal to 0.08 and 0.04 respectively. These probably are roughly the same for the NBFs. The same applies if we look at the full sample, rather than the US firms in the US. In the full sample, the difference between the large firms and the NBFs in R1 is even statistically significant. As shown in section 4, NBFs also run relatively more projects in R1. The NBFs are then consistently specialized in the areas where they also show comparatively better capabilities.

\section{FAILING AT EARLIER STAGES}

Finally, the advantages of the NBFs may not relate solely to the higher or lower probability of success of the drugs that they develop or originate. In drug R\&D, clinical trials can be very costly. Hence, other things being equal, one would prefer to 
discontinue a potentially bad project earlier rather than later. We then check whether given that a project was discontinued, the NBFs tend to discontinue them at earlier rather than later stages.

To do so, we restricted our sample to all the projects that were discontinued. We constructed a variable DISC which takes the values $0,1,2$ according to whether the project was discontinued in clinical I, II, or III. As usual, we show the results for both US firms in US trials, and for the full sample which includes European firms and European trials as well. Also, to focus on the NBFs vs large pharma comparison, we eliminated from our sample the projects originated by universities. We run multinomial logit regressions using the following variables as regressors: risk dummies, dummy for NBFs as an originator; and for our full sample regressions we added a dummy for trials in the US. The multinomial logit results are in Table 8. Table 9 reports the implied changes in probabilities.

\section{TABLE 8 AND 9 ABOUT HERE}

The results show that the projects originated by the NBFs are more likely to be discontinued at earlier clinical stages. As shown by Table 9, the probability that a project originated by an NBF is discontinued after clinicals I is about 0.22 higher than that of a large pharma; the probability that it is discontinued in clinicals I or II is about 0.12 higher for an NBF $(0.22-0.10)$. One has to be careful in interpreting these results. As discussed earlier, a project that was discontinued may not be necessarily one that failed. We know that it was discontinued by the company, and this might be because 
the company could not raise the financial resources that were necessary to continue the trials. Clearly, this problem is far more likely to occur for the NBFs than for the large pharmaceutical companies. ${ }^{13}$ This suggests that a potential source of bias is that the NBFs may discontinue projects earlier simply because they do not possess the necessary assets to continue the project rather than because the project actually failed.

However, projects are normally discontinued because the company does not think that it has good prospects to pass the later stages. An NBF is then more unlikely to discontinue a potentially good project. Put differently, discontinued projects are in any case projects that have lower expected probabilities of success. Thus, one fairly conclude that given our results in Tables 8 and 9, another potential advantage of the NBFs is that they can provide a good deal of exploration in drug research, as they produce information about potential compounds without engaging in the costly donwstream trials.

Another hypothesis is that the greater ability of the NBFs to discontinue their projects earlier could stem from the nature of their underlying knowledge basis and technology. The life sciences are strongly rooted in scientific understanding of the biological phenomena. This provides a predictive capabilities of the performance of new compounds without having to engage in long and costly tests. Similarly, the new computerized drug screening technologies, and related techniques and devices typically used by the NBFs (e.g. combinatorial chemistry), provide a significant ability to "predict the failures". In short, the knowledge basis and technologies of the NBFs encourage the possibility of trying new molecules systematically and discover relatively

\footnotetext{
${ }^{13}$ As noted in section 4, the problem is quite unlikely in the case of the large companies.
} 
early whether they are potentially valuable or not, with implied potential for greater opportunities of exploration.

\section{CONCLUSIONS}

This paper explored an unusually comprehensive data set of drug R\&D projects all over the world. Our data base enabled us to characterize several features of the potential for success of the innovation process in pharmaceuticals. Since this industry is typically characterized by the role of both larger established companies, and smaller high-tech specialist firms - the so-called NBFs - our analysis enabled us to assess the different performance of R\&D processes conducted under different governance structures - most notably projects that are fully internalized by the companies vis-à-vis projects developed in collaboration with other companies. Moreover, our data enabled to assess the different specialization and the comparative performance of different types of firms, and particularly of the large drug companies with respect to the NBFs.

Our results can be summarized as follows:

a) The NBFs are largely an American phenomenon. More than half of the drug R\&D projects originated in the US are by NBFs, while almost $90 \%$ of the drug R\&D projects originated in Europe are from established pharmaceutical firms;

b) Collaborative $R \& D$ projects are consistently more likely to occur in the US than in Europe. However, in-house projects are a significant majority of the drug R\&D projects that entered the clinical stages. 
c) The established pharmaceutical companies have comparative advantages with respect to NBFs in drug development (clinical trials).

d) In drug discovery there is no advantage related to scale. Unlike clinical developments, where the large firms seem to have superior capabilities when compared to the NBFs, there is no inherent superiority (in terms of ultimate probability of success of the compounds) between the NBFs and the large firms.

e) The NBFs and the large firms do not seem to have differential capabilities in drug research in therapeutic classes that feature higher degree of risk (R2 and R3). The NBFs however, have higher absolute capabilities in therapeutic classes with low levels of risk (R1). Consistently, they have a higher share of projects in such therapeutic classes.

f) The relatively higher share of NBF projects in R1, as opposed to R2 and R3, suggests that the NBFs do not undertake more risky projects (as noted for instance by the literature which suggests that smaller high-tech companies undertake more risky ventures). More risky projects (R3) are more likely to be undertaken by the larger pharmaceutical companies, which suggests that scale, market power, and the ability to moblise large amounts of resources are key factors in enabling the firms to sustain such higher risks.

g) Finally, other things being equal, the projects originated by the NBFs are more likely to fail at earlier clinical stages. This suggests that the NBFs perform a good deal of exploration without incurring the higher costs of failing at later stages. 


\section{APPENDIX \\ More on the "specializations" of the NBFs and the large pharmaceutical companies}

The ranking of ATC classes in terms of risk that was introduced in section 4 may be further controlled and specified by looking at an analogous classification used in Pharmaprojects (PJB Publications), one of the leading source of information on drugs in R\&D. As a whole, Pharmaprojects contains detailed information over 25,000 compounds and pharmaceutical formulations investigated since 1980, including those currently in research and those whose development has been discontinued. In addition, Pharmaprojects profiles each therapeutic category by defining the pathology in medical terms and providing a review of current treatment, epidemiological and market data, and an analysis of therapeutic trends. For each therapeutic area Pharmaprojects provides also two synthetic indices: the Novelty (N) and Market Size (M) Ratings.

On the one hand, the Novelty rating identifies the most advanced drug development strategies: highly innovative combinations of therapy and mechanisms of action received an high score, whereas the drug with a well-known strategy of action are lowranked. On the other hand, the market size rating is based on the reported world wide sales for the primary therapeutic category.

Table A1 reports the distribution of R\&D projects among the NBFs, the large pharmaceutical companies and the Universities with respect to the Risk, Market Size and Novelty classifications. The risk classification combines the novelty and the market size criteria used by Pharmaprojects. NBFs show a higher degree of innovativeness than large pharmas as they tend to apply new mechanisms of pharmacological action especially to therapies for rare pathologies (e.g. Anemia, Gaucher Disease) and niche markets (Transplant rejection of specific organs). On the contrary, large pharmas tend to be active against "pathologies that affect the masses" in larger markets, characterized by complex clinical trials and more alternative therapeutic drugs already in the marketplace. Table A 2 reports the most important products awaiting approval to be launched on the US market for deseases that have the highest need of treatment. With rare exceptions (Biomira's Theratope, Vaxgen's AIDSVAX) these products have been developed by large established pharmaceutical companies in-house or, less frequently, in collaboration with NBFs (Xolair, Visudyne, SnET2).

TABLES A1 AND A2 ABOUT HERE 


\section{REFERENCES}

Arora, A., Fosfuri, A. and Gambardella, A. (2000) Markets for Technology: Why Do We See Them, Why Don't We See More of Them, and Why Should We Care, manuscript, Carnegie Mellon University, Pittsburgh.

Arrow K.J., 1983, “Innovation in Large and Small Firms”, in Ronen J. (ed.) Entrepreneurship, Lexington Books, Lexington, Ma.

Gambardella, A., 1995, Science and Innovation in the US Pharmaceutical Industry, Cambridge, Cambridge University Press.

Gans, J., Hsu, D. and Stern, S. (2000) "When Does Start-Up Innovation Spur the Gale of Creative Destruction?" NBER Working Paper N.7851, Cambridge MA.

Hagedoorn, J. (1993) "Understanding the Rationale of Strategic Technology Partnering: Interorganizational Modes of Cooperation and Sectoral Differences" Strategic Management Journal, Vol.15, pp.371-385.

Hagedoorn, J. and Schakenraad, J. (1994) "The Effect of Strategic Technology Alliances on Company Performance” Strategic Management Journal, Vol.15, pp.291309.

Holmostrom, B. (1989) “Agency Costs and Innovation" Journal of Economic Behavior and Organization, Vol.12 (3), pp.305-327.

Kline, S. and Rosenberg, N. (1986) "An Overview of Innovation" in Landau, R. and Rosenberg, N. (eds.) The Positive Sum Strategy, National Academy Press, Washington DC.

Kogut, B. (1988) “Joint-Ventures: Theoretical and Empirical Perspectives" Strategic Management Journal, Vol.9, pp.319-333.

March J. (1991) "Exploration and Exploitation in Organizational Learning", Organization Science, Vol.1 (2), pp. 71-87.

March, J. and Levinthal, D. (1993) "The Myopia of Learning” Strategic Management Journal, Vol.14, pp.95-112.

Orsenigo L. (1989) The Emergence of Biotechnology, London, Pinter Publishers.

Pisano, G. (1997) "R\&D Performance, Collaborative Arrangements, and the Market for Know-How: A Test of the "Lemons" Hypothesis in Biotechnology", draft, Harvard Business School.

Schwartzman, D. (1976) Innovation in the Pharmaceutical Industry, John Hopkins University Press, Baltimore MD. 
Teece, D. (1986) "Profiting from Technological Innovation: Implications for Integration, Collaboration, Licensing, and Public Policy" Research Policy, Vol.15, pp.285-305. 
Table 1: $\quad$ Percentage of Projects Originated by Established Pharma, NBFs, Universities; Percentage of Licensed Projects; Percentage of Successful Projects

\begin{tabular}{lcc}
\hline & $\begin{array}{l}\text { Trials in the US/ } \\
\text { Developer is a US } \\
\text { company }\end{array}$ & $\begin{array}{l}\text { Trials in Europe/ } \\
\text { Developer is a } \\
\text { European company }\end{array}$ \\
\hline Originator: & $37.6 \%$ & $87.4 \%$ \\
Large Pharmas & $56.8 \%$ & $11.5 \%$ \\
NBFs & $5.6 \%$ & $1.2 \%$ \\
Universities & $7.5 \%$ & $2.1 \%$ \\
\% of Licensed Projects & $4.8 \%$ & $1.7 \%$ \\
By NBFs & $2.7 \%$ & $0.4 \%$ \\
By Universities & & $11.0 \%$ \\
\% of Successful Projects & $9.5 \%$ & 776 \\
N. of observations & & \\
\hline
\end{tabular}


Table 2: $\quad$ Number of Projects by NBFs, Large Pharma, Universities by classes of Risk, R1, R2, R3 - Trials in the US/ US developers

\begin{tabular}{|c|c|c|c|c|c|}
\hline Originators & Classes of Risk & R1 & $\mathrm{R} 2$ & $\mathrm{R} 3$ & Total \\
\hline NBFs & & 147 & 306 & 95 & 548 \\
\hline Large Pharmas & & 59 & 203 & 101 & 363 \\
\hline Universities & & 8 & 34 & 12 & 54 \\
\hline Total & & 214 & 543 & 208 & 965 \\
\hline
\end{tabular}

Table 3: Number of Projects by NBFs, Large Pharma, Universities by classes of Risk, R1, R2, R3 - Full Sample

$\begin{array}{lllll}\text { Classes of Risk } & \text { R1 } & \text { R2 } & \text { R3 } & \text { Total }\end{array}$

Originators

NBFs

184

394

131

709

Large Pharmas

223

703

348

1274

Universities

15

57

23

95

Total

422

1154

502

2078 
Table 4: $\quad$ Probability of Success, Licensed vs In-house Projects (Standard errors in parenthesis)

\begin{tabular}{lcc}
\hline & $\begin{array}{c}\text { US trials/ US } \\
\text { developers }\end{array}$ & Full Sample \\
\hline Prob.(Success | Compound licensed in Clinical I) & $22.0 \%$ & 20.0 \\
& $(3.8)$ & $(3.0)$ \\
Prob.(Success | Internally developed compounds) & 6.5 & 8.8 \\
& $(0.9)$ & $(0.7)$ \\
& & 86.2 \\
Prob.(Success | Compound licensed in Clinical II) & 72.7 & $(8.1)$ \\
& $(13.4)$ & 26.4 \\
Prob.(Success | Internally developed compounds that & 26.5 & $(1.8)$ \\
passed clinicals I) & $(3.1)$ & \\
& & 73.3 \\
& & $(7.2)$ \\
Prob.(Success | Compound licensed in Clinical III) & 73.3 & \\
& $(12.7)$ & 40.9 \\
Prob.(Success | Internally developed compounds that & 41.5 & $(2.4)$ \\
passed clinicals I and II) & $(4.2)$ & \\
\hline
\end{tabular}


Table 5: $\quad$ Assessing Development Capabilities, Probit Estimation - Dependent Variable: SUCC $=1$ for successful projects, 0 otherwise (Sample $=$ only licensed projects; standard errors in parenthesis)

\begin{tabular}{|c|c|c|c|c|}
\hline & \multicolumn{2}{|c|}{ US trials/US Developers } & \multicolumn{2}{|c|}{$\begin{array}{l}\text { US or EU trials/ US or EU } \\
\text { Developers }\end{array}$} \\
\hline & $\begin{array}{l}\text { Estimated } \\
\text { parameter }\end{array}$ & $\begin{array}{l}\text { Change in } \\
\text { Probability }\end{array}$ & $\begin{array}{l}\text { Estimated } \\
\text { Parameter }\end{array}$ & $\begin{array}{l}\text { Change in } \\
\text { Probability }\end{array}$ \\
\hline Const. & $\begin{array}{l}-0.08 \\
(0.37)\end{array}$ & -0.03 & $\begin{array}{c}0.42 \\
(0.33)\end{array}$ & 0.15 \\
\hline Dummy for R2 & $\begin{array}{l}-0.45 \\
(0.40)\end{array}$ & -0.15 & $\begin{array}{l}-0.33 \\
(0.26)\end{array}$ & -0.12 \\
\hline Dummy for R3 & $\begin{array}{l}-1.30 \\
(0.50)\end{array}$ & -0.43 & $\begin{array}{l}-0.89 \\
(0.30)\end{array}$ & -0.32 \\
\hline $\begin{array}{l}\text { Dummy for } \\
\text { Large Pharma }\end{array}$ & $\begin{array}{c}0.77 \\
(0.32)\end{array}$ & 0.25 & $\begin{array}{c}0.42 \\
(0.23)\end{array}$ & 0.15 \\
\hline $\begin{array}{l}\text { Dummy for } \\
\text { trials in the US }\end{array}$ & - & - & $\begin{array}{l}-0.56 \\
(0.24)\end{array}$ & -0.20 \\
\hline N.of obs. & 71 & & 164 & \\
\hline
\end{tabular}


Table 6: $\quad$ Assessing Originators Capabilities, Probit Estimation - Dependent Variable: SUCC $=1$ for successful projects, 0 otherwise (Standard errors in parenthesis)

\begin{tabular}{|c|c|c|c|c|c|c|c|c|}
\hline & \multicolumn{4}{|c|}{ US trials/US Developers } & \multicolumn{4}{|c|}{$\begin{array}{l}\text { US or EU trials/ US or EU } \\
\text { Developers }\end{array}$} \\
\hline & $\begin{array}{l}\text { Estim. } \\
\text { Param. }\end{array}$ & $\begin{array}{l}\text { Change } \\
\text { in Prob. }\end{array}$ & $\begin{array}{l}\text { Estim. } \\
\text { Param. }\end{array}$ & $\begin{array}{l}\text { Change } \\
\text { in Prob. }\end{array}$ & $\begin{array}{l}\text { Estim. } \\
\text { Param. }\end{array}$ & $\begin{array}{l}\text { Change } \\
\text { in Prob. }\end{array}$ & $\begin{array}{l}\text { Estim. } \\
\text { Param. }\end{array}$ & $\begin{array}{l}\text { Change } \\
\text { in Prob. }\end{array}$ \\
\hline Const. & $\begin{array}{l}-1.12 \\
(0.14)\end{array}$ & -0.18 & $\begin{array}{l}-1.11 \\
(0.14)\end{array}$ & -0.17 & $\begin{array}{l}-0.99 \\
(0.09)\end{array}$ & -0.19 & $\begin{array}{l}-0.99 \\
(0.09)\end{array}$ & -0.19 \\
\hline $\begin{array}{l}\text { Dummy for } \\
\text { R2 }\end{array}$ & $\begin{array}{l}-0.31 \\
(0.13)\end{array}$ & -0.03 & $\begin{array}{l}-0.32 \\
(0.14)\end{array}$ & -0.05 & $\begin{array}{l}-0.16 \\
(0.09)\end{array}$ & -0.03 & $\begin{array}{l}-0.15 \\
(0.08)\end{array}$ & -0.03 \\
\hline $\begin{array}{l}\text { Dummy for } \\
\text { R3 }\end{array}$ & $\begin{array}{l}-0.67 \\
(0.19)\end{array}$ & -0.10 & $\begin{array}{l}-0.66 \\
(0.20)\end{array}$ & -0.10 & $\begin{array}{l}-0.49 \\
(0.12)\end{array}$ & -0.09 & $\begin{array}{l}-0.52 \\
(0.12)\end{array}$ & -0.10 \\
\hline $\begin{array}{l}\text { Dummy for } \\
\text { Originator = } \\
\text { University }\end{array}$ & $\begin{array}{c}0.83 \\
(0.29)\end{array}$ & 0.13 & - & - & $\begin{array}{c}0.88 \\
(0.18)\end{array}$ & 0.17 & - & - \\
\hline $\begin{array}{l}\text { Dummy for } \\
\text { Originator = } \\
\text { NBF }\end{array}$ & $\begin{array}{c}0.05 \\
(0.13)\end{array}$ & 0.01 & $\begin{array}{l}0.05 \\
(0.13)\end{array}$ & 0.01 & $\begin{array}{c}0.12 \\
(0.09)\end{array}$ & 0.02 & $\begin{array}{c}0.12 \\
(0.09)\end{array}$ & 0.02 \\
\hline $\begin{array}{l}\text { Dummy for } \\
\text { trials in the } \\
\text { US }\end{array}$ & - & - & - & - & $\begin{array}{l}-0.15 \\
(0.08)\end{array}$ & -0.03 & $\begin{array}{l}-0.14 \\
(0.08)\end{array}$ & -0.03 \\
\hline N.of obs. & 936 & & 910 & & 2036 & & 1981 & \\
\hline
\end{tabular}


Table 7: Assessing Originators Capabilities, by Risk Category (OLSQ Estimation) (Standard errors in parenthesis)

\begin{tabular}{|c|c|c|c|c|c|c|}
\hline & \multicolumn{3}{|c|}{ US trials/US Developers } & \multicolumn{3}{|c|}{$\begin{array}{l}\text { US or EU trials/ US or EU } \\
\text { Developers }\end{array}$} \\
\hline & $\mathrm{R} 1$ & $\mathrm{R} 2$ & R3 & R1 & $\mathrm{R} 2$ & R3 \\
\hline Const. & $\begin{array}{l}0.10 \\
(0.05)\end{array}$ & $\begin{array}{c}0.08 \\
(0.02)\end{array}$ & $\begin{array}{c}0.04 \\
(0.02)\end{array}$ & $\begin{array}{c}0.13 \\
(0.03)\end{array}$ & $\begin{array}{c}0.13 \\
(0.02)\end{array}$ & $\begin{array}{c}0.08 \\
(0.02)\end{array}$ \\
\hline $\begin{array}{l}\text { Dummy for } \\
\text { Originator }=\mathrm{NBF}\end{array}$ & $\begin{array}{c}0.06 \\
(0.05)\end{array}$ & $\begin{array}{l}-0.01 \\
(0.02)\end{array}$ & $\begin{array}{c}0.00 \\
(0.03)\end{array}$ & $\begin{array}{c}0.09 \\
(0.04)\end{array}$ & $\begin{array}{l}-0.00 \\
(0.02)\end{array}$ & $\begin{array}{c}0.02 \\
(0.03)\end{array}$ \\
\hline $\begin{array}{l}\text { Dummy for trials in } \\
\text { the US }\end{array}$ & - & - & - & $\begin{array}{l}-0.03 \\
(0.04)\end{array}$ & $\begin{array}{l}-0.01 \\
(0.02)\end{array}$ & $\begin{array}{l}-0.05 \\
(0.02)\end{array}$ \\
\hline N.of obs. & 205 & 509 & 196 & 405 & 1097 & 479 \\
\hline
\end{tabular}


Table 8: $\quad$ Multinomial logit, Dependent Variable: DISC $=0,1,2$ for projects discontinued in clinicals I, II, III. Sample $=$ Discontinued Projects (Standard errors in parenthesis)

$\begin{array}{ll}\text { US trials/US } & \text { US or EU trials/ US or } \\ \text { Developers } & \text { EU Developers }\end{array}$

$1^{\text {st }}$ set of Parameters: Differences $b / w$

DISC $=1$ and baseline case DISC $=0$

Const.

$-1.10$

$(0.29)$

$-0.22$

$(0.30)$

$-1.01$

$(0.41)$

$-1.48$

$(0.26)$

$(0.20)$

Dummy for trials in the US

$-$

$2^{\text {nd }}$ set of Parameters: Differences $b / w$

$D I S C=2$ and baseline case DISC $=0$

Const.

$-0.83$

$(0.27)$

$-0.82$

$(0.17)$

Dummy for R2

$-0.66$

$-0.58$

$(0.30)$

$(0.18)$

Dummy for R3

$-0.60$

$-0.45$

$(0.34)$

$(0.20)$

Dummy for Originator $=\mathrm{NBF}$

$-1.64$

$-1.52$

$(0.26)$

$(0.21)$

Dummy for trials in the US

$-0.05$

$(0.15)$

N.of obs.

832

1759

of which

DISC $=0$

672

1292

DISC $=1$

$\mathrm{DISC}=2$

$82 \quad 242$


Table 9: $\quad$ Estimated Changes in Probabilities for NBF as Originators from the Multinomial logit Model in Table 8 (Change in Probability of failing at Stage I, II, III given that Project was originated by an NBF)

\begin{tabular}{lcc}
\hline Stage of Project Discontinuation & $\begin{array}{l}\text { US trials/US } \\
\text { Developers }\end{array}$ & $\begin{array}{l}\text { US or EU trials/ US } \\
\text { or EU Developers }\end{array}$ \\
\hline Clinicals I & 0.22 & 0.24 \\
Clinicals II & -0.10 & -0.09 \\
Clinicals III & -0.12 & -0.15 \\
\hline
\end{tabular}


Table A1: Share of projects by NBFs and large pharmas according to Risk, Market Size of the potential compounds, Novelty of the chemical structure of the molecule.

\begin{tabular}{|llrrr|}
\hline & & Low & Medium & \multicolumn{1}{c|}{ High } \\
\hline NBFs & Risk & 25,95 & 55,57 & 18,48 \\
& Market Size & 43,23 & 43,75 & 13,02 \\
& Novelty & 37,10 & 52,93 & 9,97 \\
\hline Large Pharma & Risk & 17,50 & 55,18 & 27,32 \\
& Market Size & 37,47 & 45,27 & 17,26 \\
& Novelty & 42,05 & 50,71 & 7,24 \\
\hline
\end{tabular}


Table A2: The most important programs in late-stage development (Phase III and Awaiting Approval). FDA Clinical Trials, Oct. 2000

\begin{tabular}{|c|c|c|c|c|}
\hline Market & $\begin{array}{l}\text { Product } \\
\text { Name }\end{array}$ & Description & Developers & $\begin{array}{l}\text { Development } \\
\text { Strategy } \\
\text { Novelty }\end{array}$ \\
\hline \multirow[t]{3}{*}{ Anticancer } & Theratope & $\begin{array}{l}\text { Therapeutic vaccine for } \\
\text { metastatic brest cancer }\end{array}$ & Biomira Inc. & Established \\
\hline & Faslodex & Advanced brest cancer & AstraZeneca & $\begin{array}{l}2^{\text {nd }}, 3^{\text {rd }} \text { or } 4^{\text {th }} \\
\text { Compound }\end{array}$ \\
\hline & Arzoxifene & $\begin{array}{l}\text { Selective estrogen } \\
\text { modulator }\end{array}$ & Eli Lilly \& Co. & $\begin{array}{l}2^{\text {nd }}, 3^{\text {rd }} \text { or } 4^{\text {th }} \\
\text { Compound }\end{array}$ \\
\hline \multirow[t]{3}{*}{ Respiratory } & Xolair & $\begin{array}{l}\text { First anti-immunoglobulin } \mathrm{E} \\
\text { (IgE) for asthma and } \\
\text { rhinitis }\end{array}$ & $\begin{array}{l}\text { Novartis, } \\
\text { Genentech, } \\
\text { Tanox Inc. }\end{array}$ & Leading \\
\hline & Advair Diskus & Antiasthma & Glaxo Wellcome & $\begin{array}{l}\text { New } \\
\text { Formulation }\end{array}$ \\
\hline & Asmanex & Antiasthma & $\begin{array}{l}\text { Schering-Plough } \\
\text { Co. }\end{array}$ & Established \\
\hline Cardiovascular & Vanlev & Antihypertensive & $\begin{array}{l}\text { Bristol-Myers } \\
\text { Squibb }\end{array}$ & Leading \\
\hline \multirow[t]{4}{*}{$\begin{array}{l}\text { Bacterial } \\
\text { infections }\end{array}$} & Ketek & $\begin{array}{l}\text { The first in a new family of } \\
\text { antibiotics called ketolides }\end{array}$ & Aventis & Leading \\
\hline & Cancidas & $\begin{array}{l}\text { Antifungal } \\
\text { antipneumocystic agent }\end{array}$ & Merck \& Co. & Established \\
\hline & Factive & $\begin{array}{l}\text { inhibitor of topoisomerases } \\
\text { I and IV }\end{array}$ & $\begin{array}{l}\text { SmithKline } \\
\text { Beecham }\end{array}$ & Leading \\
\hline & Spectracef & $\begin{array}{l}\text { orally-active 3rd-generation } \\
\text { cephalosporin }\end{array}$ & $\begin{array}{l}\text { TAP } \\
\text { Pharmaceutical }\end{array}$ & Established \\
\hline Depression & Vestra & $\begin{array}{l}\text { inhibits norepinephrine } \\
\text { reuptake and blocks } \\
\text { Alpha2-receptors }\end{array}$ & Pharmacia Corp. & Leading \\
\hline \multirow[t]{2}{*}{ Gastrointestinal } & Nexium & $\begin{array}{l}\text { the first proton pump } \\
\text { inhibitor developed as an } \\
\text { isomer }\end{array}$ & AstraZeneca & Leading \\
\hline & Zelmac & irritable bowel syndrome & Novartis & $\begin{array}{l}2^{\text {nd }}, 3^{\text {rd }} \text { or } 4^{\text {th }} \\
\text { Compound }\end{array}$ \\
\hline \multirow[t]{2}{*}{ Osteoporosis } & ALX1-11 & $\begin{array}{l}\text { recombinant parathyroid } \\
\text { hormones }\end{array}$ & $\begin{array}{l}\text { NPS } \\
\text { Pharmaceuticals }\end{array}$ & Leading \\
\hline & Forteo & $\begin{array}{l}\text { recombinant parathyroid } \\
\text { hormones }\end{array}$ & Eli Lilly \& Co. & $\begin{array}{l}\text { New } \\
\text { Formulation }\end{array}$ \\
\hline \multirow[t]{4}{*}{ Ophthalmic } & Memantine & glaucoma & Allergan Inc. & Leading \\
\hline & Xalcom & open-angle glaucoma & Pharmacia Corp. & Established \\
\hline & Visudyne & $\begin{array}{l}\text { age-related macular } \\
\text { degeneration }\end{array}$ & $\begin{array}{l}\text { QLT Inc., } \\
\text { Novartis }\end{array}$ & Leading \\
\hline & SnET2 & $\begin{array}{l}\text { age-related macular } \\
\text { degeneration }\end{array}$ & $\begin{array}{l}\text { Miravant Medical } \\
\text { Technologies, } \\
\text { Pharmacia } \\
\end{array}$ & $\begin{array}{l}2^{\text {nd }}, 3^{\text {rd }} \text { or } 4^{\text {th }} \\
\text { Compound }\end{array}$ \\
\hline \multirow[t]{2}{*}{ Diabetes } & Glucophage & antidiabetic & $\begin{array}{l}\text { Bristol-Myers } \\
\text { Squibb }\end{array}$ & $\begin{array}{l}\text { New } \\
\text { Formulation }\end{array}$ \\
\hline & Starlix & type-2 diabetes & Novartis & Leading \\
\hline \multirow[t]{2}{*}{ AIDS } & Trizivir & $\begin{array}{l}\text { combination of Epivir, } \\
\text { Ziagen, and Retrovir }\end{array}$ & Glaxo Wellcome & $\begin{array}{l}\text { New } \\
\text { Formulation }\end{array}$ \\
\hline & Aidsvax & preventive vaccine & VaxGen Inc. & Established \\
\hline
\end{tabular}

